\section{Plasma proteins}

The Plasma Proteins: Structure, Function and Genetic Control, Volume 1. Edited by Frank W. Putnam. Second Edition. Pp. xvi+ 481. (Academic: New York and London, October 1975.) \$37.50; $£ 19.50$.

THE appearance of volume 1 of the second edition of The Plasma Proteins is to be welcomed for several reasons. Most important is that it provides a survey of the multifarious developments which have occurred in the 15 years following the publication of the first edition. The mass of data now available finally decided the editor to subdivide the authorship so that a number of specialists are now responsible for particular chapters. As is stated in the introduction, however, this approach was adopted with some hesitation because of the danger that an integrated coverage might be lost. An initial attempt by the editor to write the whole of the second edition himself became impossible because "the rate of progress in plasma proteins outstripped my pen". Finally, in volume 1 only two chapters, constituting a general survey of the plasma proteins and a chapter on transferrin, have been written by the editor. The survey is valuable but, in view of the high price of the volume, a case can be made out that a wider readership would have been reached if this survey were to have appeared separately.

The second reason for welcoming this book is that it is well up to date. Probably because of the desirability for rapid publication, a few minor matters were not tidied up-for example, on p279 appears a warning which was already given on p272 that the iron-saturated and iron-free forms of transferrin can only be separated on starch gel if the starch is iron free. Also both Glx and Glu appear as abbreviations for glutamic acid. Table 1 of Chapter 2 represents a useful updating of the previous list of properties of plasma proteins. It is unfortunate, however, that reference to the original papers from which the data has been taken is indirect by way of another chapter in volumes 1,2 or 3 .

Since the appearance of the first edition, patient work in many laboratories has brought to light the complete sequences of a number of plasma proteins. Thus it may be appropriate to enquire as to the return which has resulted so far from this immense investment of time and energy. A positive answer in respect of the $\mathrm{H}$ and $\mathrm{L}$ immunoglobulin chains, albumin and the $\alpha_{1}$ acid glycoprotein may be given with confidence. As is explained in chapter 3, the division of the albumin molecule into domains and the structures associated with the binding sites are now known. For $\alpha_{1}$ acid glycoprotein the outcome is even more satisfactory

\section{On-line computing}

Laboratory On-Line Computing: An Introduction for Engineers and Physicists. By J. E. Brignell and G. M. Rhodes. Pp. $\mathrm{x}+297$. (International Textbooks: Leighton Buzzard, September 1975.) $£ 8.75$.

THIs book sets out to introduce engineers and physicists to on-line computing. The authors wisely confine themselves mostly to generalities but at the same time there is sufficient depth of detail to make this book of real use to persons entering this complex and rapidly developing field.

Two early chapters introduce the reader to the basic elements of both hardware and scftware, assuming a level of knowledge usually gained in most courses in engineering or physics-a good starting point. But it is in getting to grips with the real problem-hardware-software interaction-that the authors excel, with their ability to delineate and explain the essential features of interfacing. Many complex design features of both hardware and software are explained with a lucidity which is both refreshing and instructive.

The authors devote a large section of their book to a much neglected subject-the consequences of interfacing the real continuous world to the discretised world of the digital computer. The reader is introduced very gently to theories of sampling and digital filtering.

There are, however, one or two surprising omissions. There is an absence of detailed comment on, for example, either the influence of operating systems on real-time response, or on modern programming techniques which are important for memory-starved minicomputers, such as subroutine re-entrancy. On the hardware side the ubiquitous asynchronous serial line unit is not mentioned.

On the whole, however, this is an excellent book and anyone planning to "go on-line" will certainly find it of great benefit. Research workers and engineers already experienced in on-line computing will find sections which make interesting and valuable reading.
P. F. Kilty since it is now apparent that this protein is the first single-chain plasma protein having some homology with two other plasma proteins: IgG and haptoglobin. These results suggest that the time points at which each of the currently existing plasma proteins branched off from their primitive precursors will become known.

A. H. Gordon

\section{Organometallics}

Organometallic Derivatives of the Main Group Elements. (International Review of Science. Inorganic Chemistry Series Two, Vol, 4.) Edited by B. J. Aylett. Pp. 417. (Butterworth: London; University Park Press: Baltimore, Maryland, August 1975.) $£ 13.45$.

OrganOMEtallic chemists are well served by surveys intended to ease the task of keeping abreast of the flood of papers on the subject. The Annual Surveys, forming part of the Journal of Organometallic Chemistry, provide detailed coverage of derivatives of individual metals or groups of metals; the Specialist Periodical Reports of The Chemical Society cover the whole field annually; and the series of which this volume forms a part covers derivatives of the main group elements, including group IIB, biennially (organic derivatives of the transition metals are included in other volumes in the Inorganic Chemistry series).

In this volume, chapters devoted to individual metals or related groups of metals review papers published in 1971 and 1972 (for arsenic, antimony and bismuth, early 1971 to March 1973; and for beryllium, magnesium and the alkaline earths, 1969 to 1972). The surveys are inevitably selective, and the judgment of the authors in their choice of significant papers can only be tested by subsequent developments. One omission did seem surprising: although work on various metallocarboranes is reported, there is almost no coverage of carboranes per se.

If the unavoidable limitations of this type of survey are accepted, this volume provides a useful key to the original literature, and the price is not excessive. There are, however, some defects, which it is hoped the publishers and editors will remedy in future editions: the apparently random order of the chapters, and the inconsistency in their titles; the brevity of the subject index (and absence of an author index); and the fact that a survey of the literature for 1971-72 has not appeared until August 1975.

B. J. Wakefield 